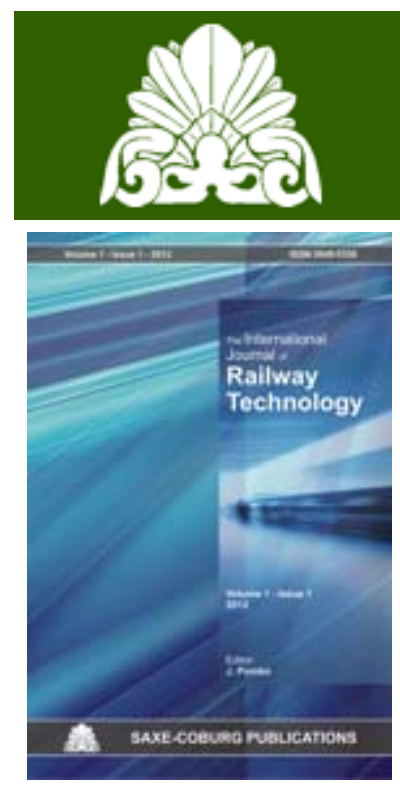

Volume 1 (2012)

Issue 1

Issue 2

\section{Links \\ Railways 2014 \\ Railways 2012 \\ IJ RT Online \\ IJ RT on CCMM \\ IJ RT Author Guide}

\section{Saxe-Coburg}

Publications

Front Page

Publications

General Info

R A I L W A Y S 20014

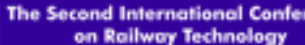

on Rollwog Technology
8-11 April 2014 - Consico, France

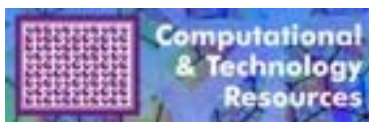

The International J ournal of

\title{
Railway Technology
}

Aims Board Submit Online Order

\section{I ntroduction}

The International Journal of Railway Technology (IJRT) is an international journal dedicated to research, development and application in the scope of railway systems. The goal of the journal is to provide an international platform for researchers and experts to promote, disseminate and discuss the recent developments and advances in the field of railway technology. Furthermore, this publication aims to encourage the interaction and collaboration between universities, research centers, railway operators and industry in order to identify problems, propose solutions and indicate directions of future research.

IJ RT is published by Saxe-Coburg Publications in print and digital versions. Four issues per annum will be published. The first issue was published in April 2012.

\section{Aims and Scope}

The journal publishes original papers that cover, but are not limited to, the following topics:

Rolling Stock

- Design, manufacture and maintenance

- Modelling and simulation

- High speed trains, light railways and freight capacity

- Performance and optimisation

- Aerodynamics and crosswind

- Noise, vibration and comfort

- Safety, security and reliability

- Ergonomics and interior design

Infrastructure

- Bridges, tunnels and transition zones

- Track design, construction and maintenance

- Interaction of vehicles with the infrastructure and the environment

- Foundations

- Track monitoring

- Trackbeds: sleepers and ties

- Geotechnical aspects: earthworks, embankments, stabilisation

- Technologies for track defects detection

Energy and Environment

- Re-use of kinetic energy

- Energy sources and smart grids

- Hybrid traction and power trains

- Sustainable rail transport

Signalling and communication

- ERTMS - European Rail Traffic Management System

- ITS - Information and Technology Systems

Operations 
- Traffic management

- Interoperability

- Intermodal solutions

Strategies and Economics

- Standards and regulations

- Capacity and cost

- Track access charges

- Future trends in railway engineering

\section{Editor}

The Editor of IJ RT is:

Dr J oao Pombo

IDMEC-IST, Lisbon, Portugal

\section{Editorial Board}

The Editorial Board of IJ RT consists of:

- Prof. A. Alonso, CAF-CEIT, Spain

- Prof. J.A.C. Ambrósio, IDMEC-IST, Portugal

- Prof. A. Bracciali, Università degli Studi di Firenze, Italy

- Prof. S. Bruni, Politecnico di Milano, Italy

- Dr R. Calçada, Universidade do Porto, Portugal

- Prof. G. Degrande, KU Leuven, Belgium

- Asst. Prof. Z. Dimitrovová, Universidade Nova, Caparica, Portugal

- Prof. J.L. Escalona Franco, Universidad de Sevilla, Spain

- Prof. E. Esmailzadeh, University of Ontario Institute of Technology, Canada

- Dr J.M. Goicolea, Universidad Politécnica de Madrid, Spain

- Prof. B. Indraratna, University of Wollongong, Australia

- Dipl.-Ing. I. Kaiser, German Aerospace Center (DLR), Germany

- Dr R. Lewis, The University of Sheffield, UK

- Dr Z. Li, Delft University of Technology, Netherlands

- Prof. Dr A. Metrikine, Delft University of Technology, Netherlands

- Prof. U. Olofsson, KTH Royal Institute of Technology, Sweden

- Dr X. Perez, CAF, Spain

- Prof. Dr O. Polach, Bombardier Transportation, Switzerland

- Prof. Dr-Ing. C. Proppe, Karlsruher Institut für Technologie, Germany

- Prof. A.A. Shabana, The University of Illinois at Chicago, USA

- Prof. R.A. Smith, Imperial College London, UK

- Prof. R. Spinola Barbosa, Escola Politécnica da Universidade de São Paulo, Brazil

- Prof. S. Stichel, KTH Royal Institute of Technology, Sweden

- Prof. Y. Suda, The University of Tokyo, Japan

- Assoc. Prof. H. Sugiyama, Tokyo University of Science, Japan

- Prof. Y. Terumichi, Sophia University, Japan

- Dr J. Tunna, Federal Railroad Administration, USA

- Prof. P.K. Woodward, Heriot-Watt University, Edinburgh, UK

- Assoc. Prof. K. Zboinski, Warsaw University of Technology, Poland

- Prof. W.M. Zhai, Southwest Jiaotong University, PR China

\section{Language}

All manuscripts must be prepared in English. 


\section{Review and Submission}

All papers submitted to IJ RT are subjected to peer-review.

Authors wishing to submit original research papers in IJ RT, should first read the author guide. The submission and review process for IJ RT is carried out using the Civil-Comp Manuscript Manager (CCMM) system.

\section{Civil-Comp}

Manuscript

Manager

\section{Online}

Present and past issues of IJ RT can be accessed online through Computational \& Technology Resources. All papers are assigned digital object identifiers (DOI).

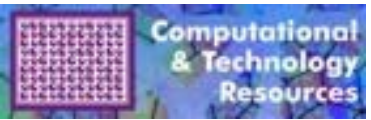

\section{Order}

IJ RT is published by Saxe-Coburg Publications in print (ISSN 2049-5358) and digital versions. The print subscription rate for 2012 will be 150 GBP. To purchase individual issues or to request information about print or digital subscriptions please contact Saxe-Coburg Publications at: ijrt@saxe-coburg.co.uk 